\title{
First karyotypical description of two American Ciconiiform birds, Mycteria americana (Ciconiidae) and Platalea ajaja (Threskiornithidae) and its significance for the chromosome evolutionary and biological conservation approaches
}

\author{
Mercival Roberto Francisco and Pedro Manoel Galetti Junior
}

\begin{abstract}
The karyotypes of Mycteria americana (Ciconiidae) and Platalea ajaja (Threskiornithidae) are described. Both species have a diploid number of $2 n=72$. There are slight chromosome morphology differences, which could be related to distinct chromosome evolution pathways of these two families. Besides a better understanding of the chromosome relationships among Ciconiiformes, this first chromosome characterization of M. americana and P. ajaja is an important tool for the conservation of both species.
\end{abstract}

\section{INTRODUCTION}

Birds of the group Ciconiiformes are highly diversified in the Americas, where they are represented by five living families out of the seven which compose this major taxon (Welty and Baptista, 1988; Sick, 1997). Most wild populations of these birds are currently vulnerable in several important ecosystems, mainly due to environmental modifications caused by human activities (Fleming et al., 1994; Gariboldi et al., 1998). The five American Ciconiiform families are found in the Pantanal floodplain which extends throughout most of the Paraguay River hydrographic basin (Sick, 1997). Both Mycteria americana (Ciconiidae) and Platalea ajaja (Threskiornithidae) are an important part of the local bird fauna because of their abundance. However, the distribution of both species in Brazil has been reduced and several local populations are threatened with extinction, or have already become extinct. Individuals of both species are currently maintained in several Brazilian zoos, which may be an important reservoir for conservation purposes.

Until now no information on the chromosomes of these two species is available, although wide karyotypic diversity has been already reported for other Ciconiiformes, including different species of the Threskiornithidae and the Ciconiidae (Takagi and Sasaki, 1974; De Boer and Van Brink, 1982; Belterman and De Boer, 1984, 1990; De Boer, 1984; Mohanty and Bhunya, 1990). It has been suggested that the karyotype pattern of Threskiornithids is derived from that of Ciconiids (Takagi and Sasaki, 1974). Nevertheless, the chromosome relationships within and between most Ciconiiform families are still poorly understood.

In order to contribute to the pool of knowledge on the chromosome evolution of Ciconiiformes, the karyotypes of Brazilian species of Mycteria americana (Ciconiidae) and Platalea ajaja (Threskiornithidae) are described for the first time in this paper and some consider- ations on the karyotypic relationship of these birds are made. This chromosome characterization can be considered the start of a genetic data-base that may prove useful for conservation of both these bird species.

\section{MATERIAL AND METHODS}

Two male and two female $M$. americana and two female $P$. ajaja captive birds of the Quinzinno de Barros Zoo of Sorocaba (SP, Brazil) were analyzed. Mitotic chromosomes were obtained from cells of the pulp of growing feathers, as described by Giannoni et al. (1993). Three to four feathers with approximately 15 days of growth were plucked from each animal. The pulp tissues were removed, gently dissociated with a metal blade and transferred to Hank's solution. Five drops of $0.0025 \%$ colchicine solution were added to the cell suspension which was then incubated at $37^{\circ} \mathrm{C}$ for $30 \mathrm{~min}$. The cellular material was transferred to $0.075 \mathrm{M} \mathrm{KCl}$ solution and incubated at $37^{\circ} \mathrm{C}$ for $30 \mathrm{~min}$, and then fixed three times in methanol-acetic acid (3:1). The chromosome preparations were stained with 5\% Giemsa phosphate, $\mathrm{pH}$ 6.8. Chromosomal morphometric analyses were performed according to Levan et al. (1964).

\section{RESULTS}

Mycteria americana (Ciconiidae) had a modal diploid number of $2 \mathrm{n}=72$ comprising macro- and microchromosomes in 105 analyzed metaphases. Chromosomes 1, $2,4,5,6,7,8$ and 10 were metacentrics, pair 3, subtelocentric, pair 9 and the $\mathrm{W}$-chromosome, telocentrics and the Z-chromosome, submetacentric. Microchromosomes were telocentric up to the point where the morphology could be identified (Figure 1). The Z-chromosome was almost the same size as chromosome 4 , while the $\mathrm{W}$ was about the same size as chromosome 9 . 
Platalea ajaja (Threskiornithidae) also had the modal diploid number of $2 n=72$ in 43 metaphases. In this species the pairs 1, 5, 8, 9, 10,11 and the Z-chromosome were metacentrics, pairs 4, 6 and 7 were submetacentrics, pair 2 was subtelocentric and pair 3 and the $\mathrm{W}$-chromosome were telocentrics. Microchromosomes were telocentrics and the $\mathrm{Z}$ - and $\mathrm{W}$-chromosomes were similar in size to chromosomes 4 and 9, respectively (Figure 2).

\section{DISCUSSION}

Because there was no previous information on the chromosomes of either species, the data presented here are important in terms of conservation, since an unequivocal chromosome characterization is the first genetic step in captive animal reproduction programs, even though the efficacy of such programs is controversial (Campbell, 1980).

Mycteria americana was found to be karyotypically identical to the previously described $M$. cinerea (Belterman and De Boer, 1990). The morphology of the macrochromosomes observed in M. americana was also similar to that of other Ciconiidae, such as Ciconia ciconia, C. boyciana, Ephipiorhynchus senegalensis (Takagi and Sasaki, 1974), C. maguari (De Boer and Van Brink, 1982), Leptotilos javanicus (Belterman and De Boer, 1984) and Jabiru mycteria (Belterman and De Boer, 1990), although there is a tendency for a reduction in the number of microchromosomes among these species, with E. senegalensis, C. boyciana and C. ciconia having $2 \mathrm{n}=68, C$. stormi and C. episcopus $2 \mathrm{n}=60$, J. mycteria $2 \mathrm{n}=56$ and $C$. nigra $2 \mathrm{n}$ $=52$. According to Belterman and De Boer (1990), the chromosome complement of $M$. cinerea may represent the ancestral karyotype of Ciconiids. The maintenance of a similar karyotype in $M$. americana suggests a conservative chromosome evolutionary pattern within this genus. Reduction in the number of microchromosomes seems to be a derived condition in the evolutionary diversification of these birds.

A decreasing number of microchromosomes seems to be a common chromosome evolutionary strategy in some other bird groups. In Accipitridae (Falconiformes), chromosome fusions involving microchromosomes have produced small- and/or medium-sized metacentric chromosomes, with a consequent decrease in the diploid number (De Boer, 1975; De Boer and Sinoo, 1984). In the Ciconiidae, however, microchromosome reduction was not followed by an increase in the number of macrochromosomes, and apparently resulted in loss of microchromosomes (Belterman and De Boer, 1990).

It has been suggested that the karyotypic diversification of Threskiornithidae is strictly related to complex serial chromosome modifications, having as a starting point the karyotype pattern found in C. boyciana with $2 \mathrm{n}=68$ (Takagi and Sasaki, 1974), which resembles a chain chromosomal rearrangement mechanism (sensu White, 1978).
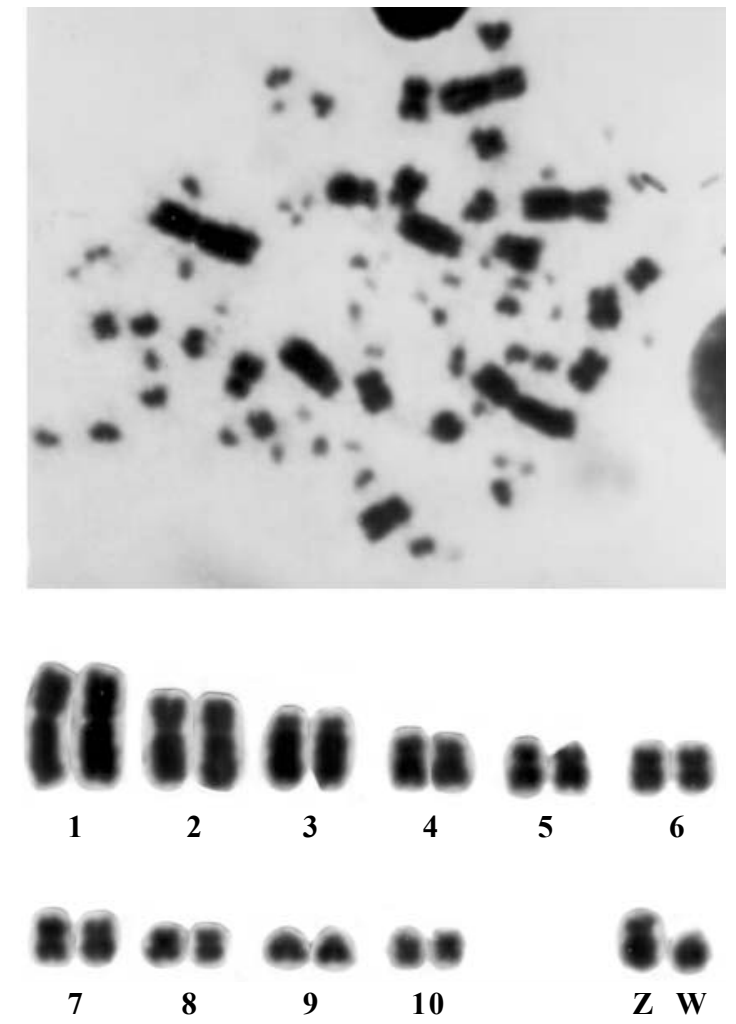

Figure 1 - Mitotic metaphase and female karyotype of Mycteria americana.
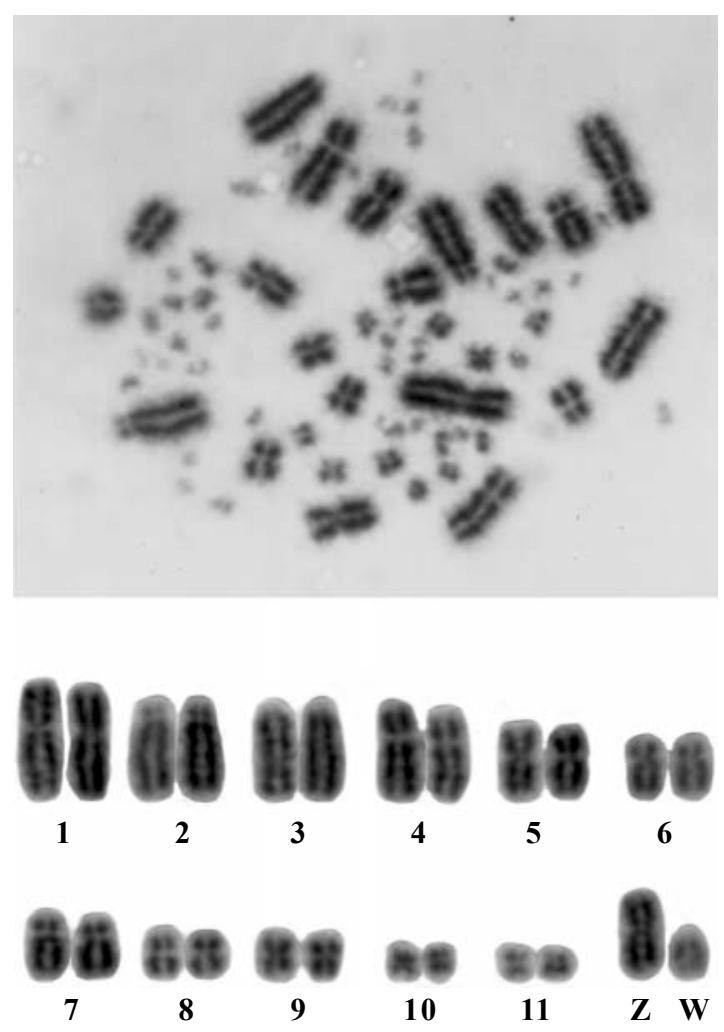

Figure 2 - Mitotic metaphase and female karyotype of Platalea ajaja. 
Centric fission of the metacentric pair number 1 of $C$. boyciana may have resulted in the two telocentric chromosome pairs of Threskiornis melanocephalus (Takagi and Sasaki, 1974). Moreover, a reciprocal centromeric translocation between the submetacentric pairs 5 and 7 of the former species may have produced the submetacentric pair 4 and the metacentric pair 7 of the latter species. From this new karyotype, in the next step, centric fusion between two telocentrics may have resulted in the submetacentric pair 4 typical of Nipponia nippon and Platalea leucorodia. Finally, a pericentric inversion could have produced the subtelocentric pair 2 present in Eudocimus ruber and Threskiornis aethiopica (Takagi and Sasaki, 1974) by a new rearrangement of this latter karyotype pattern.

The P. ajaja studied here had a karyotype similar to E. ruber and T. aethiopica, except for pairs 10 and 11 which are telocentric in the latter two species, and metacentric in the first species, and were probably derived by pericentric inversions.

Intrafamily chromosomal modifications characterized by a true chain of chromosome rearrangements appear to be much more intense among the Threskiornithidae than in the Ciconiidae, in which the chromosome evolutionary process was preferentially preceded by elimination of microchromosomes. Thus, the chromosomal evolutionary pathways of these two related groups appear to be mediated by distinct chromosome rearrangements, even though both families may be part of a unique major group of Ciconiiformes. This chromosome characterization of $M$. americana and $P$. ajaja is an important tool for further captive reproduction programs and conservation of these species.

\section{ACKNOWLEDGMENTS}

The authors thank the Quinzinno de Barros Zoo of Sorocaba (SP, Brazil) for allowing access to the birds, and the Conselho Nacional de Desenvolvimento Científico e Tecnológico (CNPq) for financial support. Publication supported by FAPESP.

\section{RESUMO}

No presente trabalho foram descritos os cariótipos de $\mathrm{Myc}$ teria americana (Ciconiidae) e Platalea ajaja (Threskiornithidae). Embora ambas as espécies tenham apresentado o número diplóide
$2 n=72$, foram observadas diferenças na morfologia cariotípica resultantes de processos evolutivos distintos que parecem ocorrer entre as duas famílias. Além de contribuir para um melhor entendimento da evolução cromossômica dentro da ordem Ciconiiformes, a caracterização cariotípica de $M$. americana e $P$. ajaja vem representar uma importante ferramenta para a realização de planos de manejo e conservação destas espécies.

\section{REFERENCES}

Belterman, R.H.B. and De Boer, L.E.M. (1984). A karyological study of 55 species of birds, including karyotypes of 39 species new to cytology. Genetica 65: 39-82.

Belterman, R.H.B. and De Boer, L.E.M. (1990). A miscellaneous collection of bird karyotypes. Genetica 83: 17-29.

Campbell, S. (1980). Is reintroduction a realistic goal? In: Conservation Biology. An Evolutionary-Ecological Perspective (Soulé, M.E. and Wilcox, B.A., eds.). Sinauer Associates Inc., Sunderland, Massachusetts, pp. 263-269.

De Boer, L.E.M. (1975). Karyological heterogeneity in the Falconiformes (Aves). Experientia 31: 1138-1139.

De Boer, L.E.M. (1984). New developments in vertebrate cytotaxonomy VIII. A current list of references on avian karyology. Genetica 65: 3-37.

De Boer, L.E.M. and Sinoo, R.P. (1984). A karyological study of Accipitridae (Aves: Falconiformes), with karyotypic descriptions of 16 species new to cytology. Genetica 65: 89-107.

De Boer, L.E.M. and Van Brink, J.M. (1982). Cytotaxonomy of Ciconiiformes (Aves), with karyotypes of eight species new to cytology. Cytogenet. Cell Genet. 34: 19-34.

Fleming, D.M., Wolff, W.F. and Deangelis, D.L. (1994). Importance of landscape heterogeneity to Wood Storks in Florida Everglades. Environ. Manage. 18: 743-757.

Gariboldi, J.C., Jagoe, C.H. and Bryan Jr., A.L. (1998). Dietary exposure to mercury in nestling wood storks (Mycteria americana) in Georgia. Arch. Environ. Contam. Toxicol. 34: 398-405.

Giannoni, M.L., Foresti, F., Falcone, C. and Tosta, P.A. (1993). An inexpensive method for chromosome preparations from feather pulp in birds, using short term treatment with colchicine in vitro, demonstrated on Amazona amazonica (Psittacidae). Rev. Bras. Genet. 16: 477-483.

Levan, A., Fredga, K. and Sandberg, A. (1964). Nomenclature for centromeric position on chromosomes. Hereditas 52: 201-220.

Mohanty, M.K. and Bhunya, S.P. (1990). Karyological studies in four species of ardeidae birds (Ardeidae, Ciconiiformes). Genetica 81: 211214.

Sick, H. (1997). Ornitologia Brasileira, uma Introdução. Ed. Nova Fronteira, Rio de Janeiro, pp. 212-220.

Takagi, N. and Sasaki, M. (1974). A phylogenetic study of bird karyotypes. Chromosoma 46: 91-120.

Welty, J.C. and Baptista, L. (1988). The Life of Birds. 4th edn. Saunders College Publishing, Orlando, pp. 19

White, M.J.D. (1978). Chain processes in chromosomal speciation. Syst. Zool. 27: 285-298

(Received April 13, 2000) 
